\title{
Queimadas nos Canaviais e Perspectivas dos Cortadores de Cana-de-açúcar em Macatuba, São Paulo'
}

\section{Sugarcane Burning and Perspectives for Harvesters in Macatuba, São Paulo}

\author{
Helena Ribeiro \\ Geógrafa. Professora titular do Departamento de Saúde Ambiental \\ da Faculdade de Saúde Pública da USP \\ Endereço: Av. Dr. Arnaldo, 715, CEP 01246-904, São Paulo, SP, \\ Brasil. \\ E-mail: lenaœusp.br

\section{Thomas Ribeiro de Aquino Ficarelli} \\ Geógrafo formado pela Universidade de São Paulo. \\ Endereço: Rua Sampaio Vidal, 388, casa I, CEP 01443-000, São \\ Paulo, SP, Brasil. \\ E-mail: thomficaळhotmail.com \\ I Projeto financiado pelo CNPq, como bolsa de Produtividade em \\ Pesquisa IC e bolsa de Iniciação Científica.
}

\section{Resumo}

A lei $n^{0}$ 11.241/2002 do estado de São Paulo proíbe a queima de cana-de-açúcar pré-colheita devido ao alto impacto que a fumaça desse processo causa na saúde coletiva e no meio ambiente. De modo gradativo, a previsão inicial era de que a proibição fosse efetiva em 2031. Posteriormente, acordo entre governo do Estado e União da Indústria de Cana-de-açúcar (Unica), estabeleceu redução do prazo para 2017. A cana-de-açúcar, quando não queimada, exige muito mais esforço dos cortadores, diminuindo a produtividade do corte manual em comparação às máquinas colheitadeiras. A ausência das queimadas traz benefícios à saúde e ao meio ambiente, no entanto, pouco ainda se sabe a respeito das consequências da mecanização para a mão de obra rural nos canaviais. Este artigo busca analisar esse quadro de incerteza sobre o que ocorrerá do ponto de vista dos cortadores de cana e o reconhecimento das consequências da lei em suas vidas. Durante a safra de cana de 2006, foram aplicados questionários a 40 cortadores de cana, de diferentes idades e gênero, no bairro Jardim América, em Macatuba-SP, em suas casas ou na rua. Perguntas qualitativas e quantitativas que abordavam temas socioeconômicos, de saúde, reconhecimento da lei e perspectivas de trabalho. Os entrevistados apresentaram um dilema entre o ar limpo e a perspectiva de trabalho. Muitos se apresentaram indecisos e sem incentivos a trabalhar em outros setores, apesar de grande parte gostar do local onde vive e se interessar por continuar a trabalhar na agricultura.

Palavras-chave: Trabalhador rural; Saúde ambiental; Queima de cana-de-açúcar; Estado de São Paulo. 


\section{Abstract}

Law no. 11241/2002 of the State of São Paulo prohibits sugarcane burning before harvest because of its high environmental and health impacts. Initially, burning should be gradually eliminated by 2031 . Later, an agreement between the State Government and the Sugarcane Industry Union reduced this deadline to 2017. Sugarcane harvesting without burning requires more effort and reduces labor productivity, favoring the adoption of mechanical harvest. The absence of burning favors health and the environment; however, little is known about what will happen to harvesters as a consequence of the introduction of mechanical harvesters. This article aims to analyze this picture of uncertainties about what will happen to this population based on their point of view. During the sugarcane harvest period in 2006, questionnaires were administered to 40 harvesters, of different ages and genders, at their homes or on the street, in the Jardim America neighborhood, in Macatuba, State of São Paulo. Questions referred to social and economic aspects of their lives, health, knowledge of the Law and work perspectives. Interviewed workers presented a dilemma between clean air and work perspectives. Many of them do not receive incentives to work in other sectors, in spite of the fact that most of them like the city where they live and are interested in continuing to develop agricultural activities.

Keywords: Rural Worker; Environmental Health; Sugarcane Burning; State of São Paulo.

\section{Introdução e Objetivos}

O fato de o Brasil usar, popularmente, álcool como combustível coloca-o numa posição vanguardista em energias alternativas à de material fóssil "convencional”. Intenso uso de energia de combustíveis fósseis apresenta problemas para a humanidade, entre eles, altos custos, poluição do ar, aquecimento global, riscos de segurança, depleção de recursos não renováveis e desigualdade (Geller, 2003). Mercados para o etanol estão em ascensão no mundo e no Brasil, sobretudo por causa do aumento das vendas de veículos flex-fuel, que atualmente correspondem a 80\% da produção de automóveis no país. De 2004 a 2007, o número de veículos flex-fuel novos, registrados no país, passou de 278.764 para 1.780 .876 (dados Anfavea in Unica, 2009).

Em 2005, foram produzidas cerca de 1.011.580 milhões de toneladas de cana-de-açúcar em todo o mundo. No Brasil, foram 422.926 milhões de toneladas, equivalentes a $42 \%$ do total mundial, sendo o país já o maior produtor ${ }^{2}$. 0 estado de São Paulo é responsável por $55 \%$ da produção nacional e $24 \%$ da mundial. Há tendência de expansão devido à demanda e à adaptação do cultivo a outras regiões. Em 2008, a produção brasileira alcançou 648.847.700 toneladas e para 2009 a previsão de safra é de 674.659.345 t, numa área de 61 milhões de hectares ${ }^{3}$. Substituição de culturas e avanço em áreas de pastagens trarão grandes transformações na atividade econômica desses locais e ocasionarão novas condições de trabalho com reflexos no cotidiano de várias cidades de pequeno e médio porte. Na maior parte das áreas, esse tipo de prática agrícola não beneficiou as populações locais, sobretudo as dos pequenos centros urbanos do estado de São Paulo, cujas economias mantêm-se estagnadas, concomitantes a um processo de degradação ambiental devido à poluição atmosférica e à simplificação dos ecossistemas 4 . São restritos os estudos sobre esses municípios que, sob o impacto da concentração fundiária e econômica, vêm enfrentando um círculo vicioso de desemprego, pobreza e degradação

\footnotetext{
2. FAO, 2005 - Food and Agriculture Organization

3 IBGE - Instituto Brasileiro de Geografia e Estatística. http://www.ibge.gov.br.estatisticas.indicadores.agropecuaria. Acesso em 3/5/2009.

4 A simplificação é característica das monoculturas. Nesse caso, a vegetação original do espaço, caracterizada pela sua biodiversidade, foi submetida a uma racionalidade econômica que não privilegiou essas características.
} 
ambiental. Além disso, pouca atenção política vem sendo dada a eles.

A cana-de-açúcar (Saccharum sp) é uma planta bastante rígida com tecidos resistentes e elásticos, o que dificulta seu corte. A maior parte da cana-deaçúcar no Brasil é colhida manualmente. A queima das lavouras na pré-colheita torna a planta mais quebradiça, maximizando a capacidade de corte e reduzindo o tempo de colheita. Quando a cana é cortada verde, sem queima, a produtividade média do cortador pode cair até $1 / 5$. A queima da cana traz algumas vantagens agrícolas, além da facilitação do corte. De acordo com Delgado in Ripoli (2002), há incorporação da palha ao solo aumentando o teor de matéria orgânica; destruição dos inimigos naturais, como broca da cana; facilitação das operações de preparo de solo e de cultivo; colaboração na eliminação das pragas da cultura, demandando menos agrotóxicos; eliminação de animais peçonhentos, evitando acidentes com cortadores.

Entretanto, diversas pesquisas (Zancul, 1998; Ribeiro e Assunção, 2002; Arbex, 2001; Ribeiro, 2008; Lopes e Ribeiro, 2006; Arbex e col., 2004; Cançado e col., 2006) apontaram consequências negativas das queimas nas zonas canavieiras, sobretudo na saúde da população e no meio ambiente. Apesar de não ser homogênea, a fumaça carrega partículas carbonizadas (carvãozinho), pó, fiapos de palha e gases nocivos à saúde, como óxidos nítricos (NO), hidrocarbonetos (HC), dióxido de nitrogênio ( $\mathrm{NO}_{2}$ ) e monóxido de carbono (CO) (Ribeiro e Assunção, 2002). Dentre as consequências à saúde, são frequentes: irritação nos olhos, ataques de asma, falta de ar, tosse, dores de cabeça.

$\mathrm{Na}$ época das queimadas, o meio ambiente e o cotidiano das pessoas também podem sofrer consequências negativas, como enfatiza Zancul (1998):

- mudanças no microclima das zonas canavieiras, afetando o ciclo hidrológico e a incidência de radiação solar;

- aumento de incidência de doenças respiratórias na população da região, tornando maior a procura por postos de saúde e hospitais;

- danos à flora e à fauna;

- prejuízos à estética do meio ambiente;

- aumento da erosão por gotas de chuva, devido ao solo estar descoberto;

- desequilíbrio ecológico de insetos, aves, répteis e plantas;

- aumento de acidentes em estradas da região, pela redução de visão causada pela fumaça;

- sedimentação de poeira por cidades próximas, sujando casas e calçadas.

Os canaviais ocupam, majoritariamente, as porções central e oriental do estado de São Paulo, conforme observado na figura 1. Recentemente,

\section{Figura I - Áreas canavieiras no estado de São Paulo na safra 2008/2009}

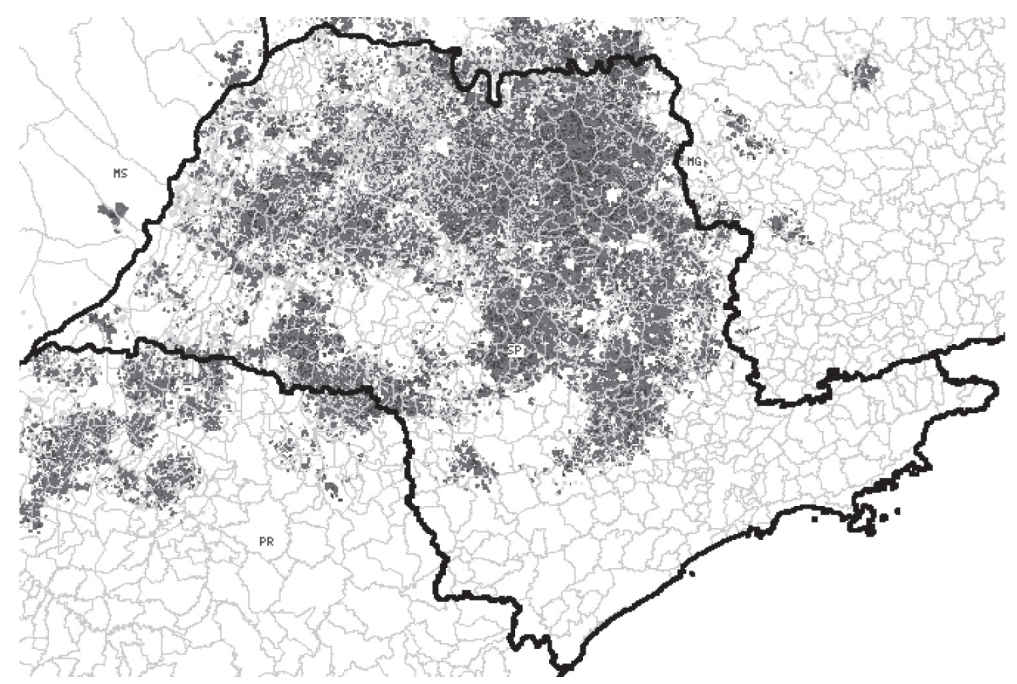

Fonte: Canasat, 2009. 
houve expansão para o oeste, sobretudo em áreas com pecuária bovina.

Lopes e Ribeiro (2006), ao mapearem as queimadas e a incidência de internações por doenças respiratórias nas diferentes regiões do estado, observaram que nas zonas canavieiras a incidência desses dois fenômenos é maior, sobretudo nos meses de seca e de queimadas (entre maio e outubro).

No município de Araraquara, onde há 32.470 hectares plantados de cana-de-açúcar ${ }^{5}$, Arbex e colaboradores (200o) estudaram a quantidade de pacientes atendidos para inalação num hospital da cidade. Verificaram que a quantidade de pessoas atendidas por dia nos finais de semana em maio e junho (época das queimadas e safra) variava entre 70 e 40 pessoas, e que, com o final da safra, a média caía para 10 a 20 pessoas. Os autores indicam a queima nos canaviais como motivo desse aumento sazonal.

Diante dos prejuízos causados pelas queimadas, foi outorgada a lei estadual $\mathrm{n}^{0} 11.241$, proibindo gradativamente a queima das culturas de cana-deaçúcar no estado. A Secretaria do Meio Ambiente foi encarregada de fiscalizar as queimadas e a Secretaria da Agricultura, de acompanhar a modernização das atividades e o impacto do fim das queimas na cadeia produtiva $^{6}$. 0 Quadro 1 mostra o cronograma da lei a ser obedecido pelos produtores de cana. A justificativa da lei é que as queimadas prejudicam a saúde da população e a atmosfera, agravando o efeito estufa ${ }^{7}$. As datas da proibição total da queima foram contestadas pelos produtores de cana, sendo um dos motivos apontados o alto custo ${ }^{8}$ da colheitadeira, em substituição ao corte manual. Entretanto, uma colheitadeira colhe até mil toneladas de cana por dia, substituindo mais de oitenta cortadores manuais ${ }^{9}$. De modo gradativo, a previsão inicial era de que a proibição total fosse efetiva em 2031. Posteriormente, acordo entre governo do estado e a União da Indústria de Cana-de-açúcar (Unica), estabeleceu redução do prazo para 2014 em áreas mecanizáveis e 2017 em áreas mais íngremes não mecanizáveis (Unica, 2009).

Silva (2005) indicou que as condições de trabalho dos cortadores de cana são péssimas, tendo sua vida útil comparada à de um escravo na época do Brasil Colônia. A autora apontou denúncias do Ministério Público e da imprensa sobre as más condições de trabalho e de vida desses cortadores, a maioria migrante. Os fatos de, em muitos casos, quantidade mínima de corte ser exigida do cortador e ele poder facilmente ser substituído por outro mais produtivo fazem com que ele entre num ciclo vicioso, no qual, se não trabalhar, não sobreviverá. Alves (2006)

\section{Quadro I - Cronograma de eliminação da queimada em área de canavial}

\begin{tabular}{|c|c|c|}
\hline Ano & Área mecanizável onde não se pode efetuar a queima da cana & Percentagem de eliminação da queima \\
\hline 2006 & $30 \%$ da área cortada & $30 \%$ eliminada \\
\hline 2011 & $60 \%$ da área cortada & $60 \%$ eliminada \\
\hline 2021 & 100\% da área cortada & $100 \%$ eliminada \\
\hline Ano & $\begin{array}{l}\text { Área não mecanizável, com percentagem de eliminação (declividade } \\
\text { superior a } 12 \% \text { e/ou menor de } 150 h a \text { ) }\end{array}$ & Onde não se pode efetuar a queima \\
\hline 2011 & $30 \%$ da área cortada & $30 \%$ eliminada \\
\hline 2021 & $60 \%$ da área cortada & $60 \%$ eliminada \\
\hline 2031 & 100\% da área cortada & $100 \%$ eliminada \\
\hline
\end{tabular}

Fonte: Diário oficial do Estado de São Paulo.

\footnotetext{
5 IBGE, 2006.

6 Artigo 11 da lei $n^{0} 11.241$ de 19 set. 2002, do estado de São Paulo.

7 Diário Oficial do Estado de São Paulo. 8 fev. 2007, p. 14.

8 Estima-se entre R\$ 1.00o.ooo,oo e R\$ 500.0oo,oo dependendo do modelo, eficiência e tamanho.

9 Case IH Agriculture. Folheto distribuído a produtores em feira na cidade de Ribeirão Preto-SP.
} 
aponta as principais causas que levaram à morte 13 cortadores de cana durante a safra 2004/2005, no estado de São Paulo: o trabalho pago por produção e a busca de remuneração suficiente. Compara dados das décadas de 1950 e 1960, quando a média era de 3 $\mathrm{t} /$ pessoa/dia de cana cortada, com os atuais $12 \mathrm{t}$ /pessoa/dia (em média), e afirma que a exigência atual de produção causa excesso de fadiga. A morte seria em decorrência de deficiência do funcionamento de órgãos, causada pelo enorme esforço físico feito pelos cortadores para cortar mais e ganhar mais.

Entretanto, a lei da proibição das queimadas aos poucos tem sido aceita por fazendeiros e empresários do setor e o investimento em máquinas colheitadeiras tem crescido. A área colhida de cana crua e mecanizada tem apresentado aumento percentual expressivo no estado, pois representava $34,2 \%$ na safra de $2006 / 2007$ e $49,1 \%$ na de $2008 / 2009$. Inversamente, a percentagem de área colhida com fogo prévio reduziu-se de 65,8\%, na safra 2006/2007, para 50,9\%, na safra 2008/2009 (Governo do Estado de São Paulo, 2009).

A população de trabalhadores rurais do setor vive momentos de incertezas, pois não havendo a opção do trabalho do corte, busca novas opções de trabalho. Pouco se sabe sobre as perspectivas de inclusão dos cortadores de cana na economia. Os canaviais constituem importante fonte de emprego para uma fração da população com baixo nível de instrução. Representam a maior demanda de força de trabalho agrícola no estado de São Paulo, com o equivalente de 250.907 homens/ano, em 2002, 35\% de toda força de trabalho agrícola (Braunbeck e Magalhães, 2004). Segundo Vilas Boas e Dias (2009), apesar de não se conhecer bem o perfil dos trabalhadores envolvidos no setor sucroalcooleiro, no Brasil, estima-se que nas atividades de corte estejam envolvidos aproximadamente 335 mil trabalhadores. Do ponto de vista ambiental, a eliminação das queimadas é uma vitória para a população que habita as zonas sucroalcooleiras, incluindo os cortadores, porém, socialmente, a mecanização poderá marginalizar essa população, se propostas alternativas de trabalho e de inclusão social não forem pensadas, planejadas e implementadas.

O objetivo deste artigo é retratar a atual situação em que vivem os trabalhadores rurais de uma zona sucroalcooleira, observando suas condições econômicas, sociais, ambientais e de saúde, no contexto da implementação da lei que proíbe a queima da cana na pré-colheita e da mecanização do corte, que causam o fim desse tipo de emprego.

\section{Materiais e Métodos}

O local selecionado para trabalho de campo foi o município de Macatuba, no estado de São Paulo. Durante período de safra de cana, foram entrevistados alguns atores-chave do processo e aplicados questionários com 58 questões (abertas e fechadas), algumas com subitens, a cortadores de cana, em bairro residencial da cidade, Jardim América, indicado pelo Sindicato dos Trabalhadores Rurais como o de maior predominância de cortadores de cana. Iniciou-se a aplicação a partir de uma praça central do bairro, percorrendo-se as ruas que irradiavam daí e batendo-se nas portas das residências de cortadores, durante dois dias. Muitos cortadores não tinham ido trabalhar, por falta de trabalho ou problema de saúde, o que permitiu que eles respondessem às perguntas. Nos dois dias posteriores, os questionários foram aplicados, ao final do dia de trabalho, a cortadores que desciam dos ônibus que os traziam do corte na lavoura, em rua principal do mesmo bairro. No total, 40 cortadores de diferentes idades e gênero responderam às questões.

O projeto foi aprovado pelo Comitê de Ética da Faculdade de Saúde Pública. Os entrevistados assinaram termo de consentimento livre e esclarecido.

\section{Aspectos Econômicos, Sociais e Geográficos do Município de Macatuba}

O município de Macatuba se situa na porção central do estado de São Paulo. Possui cerca de 17.0oo habitantes e ocupa área de $226 \mathrm{~km}^{2}$. Da área municipal, $151 \mathrm{~km}^{2}$ são cultivados pela monocultura de cana-deaçúcar, correspondendo a aproximadamente dois terços do território. As áreas restantes são ocupadas por cerrado, vegetação rasteira, zona urbana e uma mínima parte por culturas de milho e amendoim. A economia é voltada ao setor sucroalcooleiro, responsável por empregar grande parte da população. Em 2003, o setor agropecuário (fortemente baseado no cultivo da cana) e o setor industrial (baseado 
nas usinas sucroalcooleiras lá instaladas) juntos movimentaram 150 milhões de reais na cidade, com produção de 1.162 toneladas de cana-de-açúcar (IBGE, 2006).

A paisagem rural é bastante homogênea, com preponderância de canaviais e de algumas usinas sucroalcooleiras intercaladas. Os arredores do município também são ocupados predominantemente por canaviais. A monocultura de cana começou a ser praticada com maior intensidade na região devido ao programa Pró-álcool, lançado pelo Governo Federal na década de 1970. Tendo passado por uma crise no final da década de 1980, atualmente proprietários de terra e empresários possuem interesses comuns no desenvolvimento do setor sucroalcooleiro. Como a região é bastante homogênea em termos de uso do solo, o mercado de trabalho também é bastante concentrado no setor. A partir de 1970, era procurada mão de obra para cortar cana por baixo custo, enquanto muitos migrantes e ex-pequenos proprietários da região procuravam emprego. Começou então a ser formada uma comunidade de cortadores de cana na cidade de Macatuba, que, atualmente, corresponde a aproximadamente 2.000 pessoas. Se calcularmos uma média de 4 pessoas para cada um desses chefes de família, veremos que, aproximadamente, 8.ooo pessoas, dentre os 17.000 habitantes, dependem do corte da cana. 0 restante da população ativa trabalha em pequeno comércio ou com serviços em geral.

\section{Resultados}

\section{A comunidade de cortadores de cana e a cidade}

Durante esses aproximados 40 anos de existência da comunidade cortadora e de trabalhadores rurais da cana-de-açúcar, em Macatuba, muitos aspectos foram modificados, acompanhando o que ocorria com outros grupos de cortadores pelo estado: reivindicação de melhores condições de trabalho e de leis trabalhistas, construção planejada de moradias pelo poder público para abrigar a nova população, criação de sindicato. Algumas das conquistas dos cortadores no estado foram: carteira de trabalho assinada, jornada de até 8 horas de trabalho por dia, salário medido segundo a quantidade de metros cortados de cana (Alves, 2006). A primeira medição em campo é feita pela metragem cortada que é convertida em toneladas cortadas por dia, essa conversão é baseada em cálculos e regras de três. A maior parte dos trabalhadores não tem controle da pesagem de sua produção diária (Mendonça, 2006). A partir de 1986, um acordo passou a permitir que os trabalhadores participassem do processo de conversão do valor de metro cortado para tonelada, feito pelo departamento técnico das usinas. Porém, isso não acontece na realidade, pois os trabalhadores perdem o dia de trabalho para acompanhar o processo (Vilas Boas e Dias, 2009). Também é corrente no estado o pagamento de um piso mínimo que é acrescido ao pagamento por tonelada cortada por dia (Mendonça, 2006).

A maior parte das casas no bairro foi construída pelo governo do estado, por meio de mutirões e financiamentos. Todas elas são de alvenaria e possuem água encanada, teto forrado e fogão a gás. As casas visitadas possuem, em média, 3 a 6 cômodos e um quintal com plantas ou de terra batida, com banquinhos para receber visitas, conversar ou passar o tempo de lazer. Dos cortadores entrevistados, 70\% são proprietários das casas onde moram, tendo financiado a casa em até 10 anos. As casas alugadas representaram 17,5\% e as cedidas 10\%. Em geral, são de propriedade de outros cortadores, que as compraram poupando parte do salário ao longo dos anos. Essa é uma condição específica de trabalhadores residentes no estado e diferencia-se de condições de moradia de migrantes que, segundo Silva (2005), são precárias e subumanas.

Por serem predominantes, os cortadores de cana participam ativamente do cotidiano do bairro e avaliam positivamente diversos aspectos da cidade. Grande parte deles se diz contente com as condições locais, como é possível ver na tabela 2. De modo geral, disseram não ter necessidade de ir a cidades grandes próximas, como Bauru ou Avaré, pois muitos dos serviços e mercadorias de que necessitam são encontrados em Macatuba. Costumam ir para essas cidades em raras ocasiões, por exemplo, para visitar parentes, tratamentos de saúde mais específicos, ou para procurar mercadorias mais raras ou de menor custo. Eles se dizem bastante contentes com o convívio social da cidade, o que colabora na formação de um espaço comum em que todos têm o direito de participar e agir. No bairro, era comum observar que as pessoas se conheciam, que frequentemente 
Tabela I - N de cortadores segundo avaliação dos aspectos cotidianos. Macatuba, SP, 2006

\begin{tabular}{lcccc} 
& Contentes & Descontentes & Indiferentes & Total \\
Distância da cidade grande & 31 & 5 & 4 & 40 \\
Distância do trabalho & 31 & 4 & 5 & 40 \\
Convívio social & 37 & 1 & 2 & 40 \\
Formação dos filhos & 32 & 4 & $4^{*}$ & 40 \\
Diversão/entretenimento & 18 & 17 & 5 & 40 \\
\hline
\end{tabular}

*Trata-se de pessoas que não têm filhos.

Tabela 2 - $\mathbf{N}^{\circ}$ de cortadores segundo razões para morar em Macatuba, SP, 2006

\begin{tabular}{lcc} 
Motivos que os levaram à região & N & $\%$ \\
Migração dos pais & 15 & 37,5 \\
Emprego/serviços & 9 & 22,5 \\
Nasceram na região & 12 & 30,0 \\
Outros & 4 & 10 \\
\hline Total & 40 & 100 \\
\hline
\end{tabular}

apareciam visitas nas casas durante as entrevistas, e que conversas ocorriam em frente às residências ou entre vizinhos.

Quanto às opções de lazer, alguns afirmaram que nunca havia festas ou eventos, outros que sempre havia algo de interessante para se fazer à noite ou nos finais de semana. Os jovens se mostraram mais descontentes com as opções de lazer que os adultos e idosos.

\section{Vida dos cortadores}

Dentre os entrevistados, 27 eram do gênero masculino e 13 do feminino. Como recebem de acordo com o que cortam, os homens conseguem salários até o dobro maiores do que o das mulheres, devido à força física que esse trabalho exige. Por esse motivo, há menos mulheres interessadas e algumas só trabalham poucos meses do ano, ou então não trabalham para cuidar da casa e dos filhos.

O aumento da meta do corte da cana causou grande diminuição no número de mulheres que realizam esse trabalho. Além disso, a dupla jornada (obrigação com o trabalho na cana, com o serviço em casa e com o cuidado e educação dos filhos) significa um esforço muito maior para as mulheres que, mesmo com todas as dificuldades, enfrentam o trabalho bruto (Mendonça, 2006).
A totalidade dos entrevistados estava morando com a família, na condição de pais, parentes ou filhos. Os solteiros ou divorciados costumavam morar com a família dos irmãos ou dos primos.

o fluxo migratório inter-regional era restrito dentre os moradores de Macatuba, pois a totalidade dos entrevistados morava e trabalhava na região.

A procedência dos cortadores entrevistados é bastante diversa: 37,5\% do Paraná, 17,5\% de Minas Gerais e 2,5\% de Alagoas. Haviam nascido no estado de São Paulo 42,5\% deles. Essa situação é característica de muitos centros urbanos de menor porte do estado de São Paulo, em que a mão de obra rural vive na área urbana e tem raízes locais ou no Sul e Sudeste do país. Diverge de outras cidades de maior porte, como Piracicaba, Jaú, dentre outras, em que há vinda de migrantes sazonais do Nordeste do país para o corte. Segundo Silva (2005), estudo da Pastoral relata que os migrantes constituem a maior parte dos empregados no corte da cana. A autora aponta que, ao lado da precarização das relações de trabalho, há uma segmentação da força de trabalho entre migrantes e não migrantes e entre os trabalhadores de fora e os locais. "Os locais geralmente são descendentes de migrantes de outras regiões do país que vieram para São Paulo e se estabeleceram definitivamente a partir das décadas de 1960 e 1970" (Silva, 2005, p.18). 
Grande parte dos cortadores (6o\%) entrevistados, ou seus pais, migraram para Macatuba devido à oferta de serviço no corte de cana, que não necessitava conhecimento técnico. Dos entrevistados que nasceram na região, alguns disseram que seus pais provinham de outras regiões do estado de São Paulo ou de outros estados, e afirmaram que também eram praticantes do corte.

A totalidade dos entrevistados referiu ter experiência com agricultura em sítios ou em grandes lavouras antes de vir morar em Macatuba. A demanda do setor sucroalcooleiro por mão de obra para o corte tornou-se uma oportunidade alternativa para aqueles que estavam em dificuldades no campo.

No corte, medido e pago pela capacidade de cortar por dia útil, a faixa etária dos cortadores é bastante variada. A idade média dos entrevistados variou entre 20 e 35 anos, (Figura 2), porém foram encontrados indivíduos com mais de 60 anos que ainda cortavam cana frequentemente, por ser essa a opção mais comum de obtenção de renda que a região oferece para pessoas dessa faixa etária e com baixa escolaridade. Em geral, os mais capazes de cortar são jovens do sexo masculino, que veem no corte uma oportunidade de realizar planos de constituir família ou de ajudar na renda familiar, uma vez que exige bastante força e preparo físico.

O grau de instrução da população entrevistada é bastante variado. Quanto mais jovem mais tempo permaneceu na escola, enquanto alguns dos mais velhos são analfabetos. A maioria não completou o ensino fundamental (Tabela 3). Nenhum dos 40 entrevistados relatou estar cursando alguma atividade educativa e o principal motivo alegado é o cansaço após o trabalho. Apesar de alguns analfabetos declararem interesse em aprender a ler e escrever, eles relataram não estudar por falta de disposição ou de incentivo. Justificaram não terem frequentado a escola por mais tempo pela falta de apoio da família e pelo baixo salário recebido pelos pais e irmãos, o que levava à necessidade de colaborar com a renda familiar. Para os entrevistados adultos, que possuíam filhos, a frequência escolar foi extremamente valorizada, pois eles querem que seus filhos alcancem melhores condições, por isso todos estão matriculados na escola.
Figura 2 - $\mathrm{N}^{\circ}$ de cortadores de cana segundo faixa etária dos entrevistados

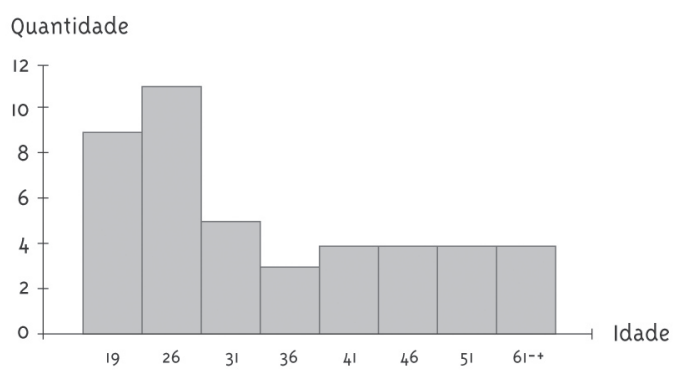

Tabela 3 - $\mathrm{N}^{\circ}$ e \% de cortadores entrevistados segundo escolaridade. Macatuba, 2006

\begin{tabular}{lcc} 
Escolaridade & N & $\%$ \\
Analfabeto & 10 & 25,6 \\
Ensino fundamental incompleto & 22 & 56,4 \\
Ensino fundamental completo & 2 & 5,1 \\
Ensino médio cursado & 5 & 12,8 \\
\hline Total & 39 & 100 \\
\hline
\end{tabular}

Como já mencionado, os cortadores moram com parentes que, na maioria, exercem atividades remuneradas, em geral, também no corte. Em alguns casos, os parentes têm atividades que exigem maior conhecimento técnico, como dirigir tratores ou inspecionar a produção de álcool na usina (tabela 4). Segundo os entrevistados, a abertura de uma fábrica de vestuário na cidade vem se tornando uma opção alternativa de emprego, principalmente para mulheres jovens.

\section{Tabela 4 - $\mathrm{N}^{\circ}$ de cortadores segundo profissão dos parentes dos cortadores. Macatuba, 2006}

\begin{tabular}{lc} 
Profissão do parente & N \\
Cortador & 19 \\
Técnico em usina & 3 \\
Diarista & 1 \\
Costureira & 2 \\
Servente de obra & 2 \\
Setor agrícola & 1 \\
Setor industrial & $3^{*}$ \\
Setor de serviços & 2 \\
\hline Total & 33 \\
\hline
\end{tabular}

*Trabalham em uma fábrica de calça jeans próxima ao bairro. 


\section{0 trabalho}

Todos os cortadores necessitam de condução para se deslocar ao local de trabalho. Eles acordam aproximadamente às 5 h da manhã para estarem prontos para o ônibus, que os busca às $6 \mathrm{~h}$, e chegam ao canavial às 7 h. Eles levam marmita para o almoço, água fresca, roupas para conter o suor do corpo e facão, no caso dos empregadores não oferecerem.

A jornada de trabalho costuma ser de 8 horas por dia, sendo, em alguns casos, de 7 ou de 9 horas (sem levar em conta o tempo necessário de transporte para o local de trabalho). Os cortadores, por ganharem por produção, possuem a opção de trabalhar mais ou menos horas em certos dias, porém, quando estão oficialmente contratados, devem cumprir uma carga horária semanal mínima (numa média de 8 horas por dia), ou então uma quantidade de cana cortada mínima. Dentre os entrevistados, exceto um indivíduo, todos disseram trabalhar 6 dias por semana. Alguns têm direito a um dia de folga para cada 5 dias trabalhados. Segundo Mendonça (2006), na folga 5 por 1 , a cada dia de folga, só um pequeno grupo pode se reunir. Isso diminui o convívio social, familiar e a possibilidade de organização política. Somente as usinas ganham com esse sistema, pois exclui a exigência de pagamento de horas extras nos finais de semana.

Os cortadores, durante o trabalho, são observados por fiscais que acompanham o rendimento de cada um e calculam, ao final do dia, a quantidade cortada por cada um para o acerto de contas no final do mês. Quanto ao tratamento que os cortadores recebem desses fiscais, há opiniões controversas, que variam desde "muito simpáticos" até "eles nos tratam como cachorros", dependendo da empresa contratante. Os cortadores podem ser contratados diretamente pelo proprietário da terra onde costumam cortar, ou então por meio de empresas terceirizadas que fazem as contratações e se encarregam dos recursos humanos. Em Macatuba, ambas são comuns.

A tabela 5 mostra que a maioria dos cortadores recebe somente os acessórios básicos para o trabalho gratuitamente dos empregadores, sobretudo facões e botas. Uma minoria recebe benefícios, como cesta básica, alimentação no trabalho, vale alimentação e remédios. Mesmo água, durante a jornada de trabalho, não é disponibilizada para todos e, segundo os entrevistados, quando é disponibilizada, fica no ônibus e acaba esquentando pela exposição ao sol. Assim, todos afirmaram levar sua própria garrafa térmica com água de casa. Relataram que, em anos anteriores, era distribuído suco durante a jornada de trabalho, mas que essa prática não ocorre mais.

\section{Tabela $5-\mathbf{N}^{\circ}$ de trabalhadores segundo benefícios recebidos, Macatuba}

\begin{tabular}{lccc} 
Benefício & Sim & Não & Total \\
Cesta básica & 6 & 34 & 40 \\
Alimentação no trabalho & 5 & 35 & 40 \\
Vale alimentação & 6 & 34 & 40 \\
Remédio gratuito & 6 & 34 & 40 \\
Água & 18 & 22 & 40 \\
Facão & 33 & 7 & 40 \\
Acessório (roupa, bota, etc.) & 35 & 5 & 40 \\
Ginástica laboral & 9 & 31 & 40 \\
\hline
\end{tabular}

Somente um, dentre os 40 entrevistados, disse estar trabalhando sem carteira assinada. A lei e o sindicato local exigem que todos os empregadores registrem os cortadores contratados e que obedeçam às leis trabalhistas. Porém, os benefícios ficam exclusivamente a critério dos contratadores, franquias e empresas.

A colheita de cana é efetuada, em Macatuba, geralmente entre maio e outubro. Em poucas ocasiões, em alguns canaviais, a cana é colhida em abril ou novembro. Durante os meses em que não há colheita, os cortadores se ocupam com outras atividades para manter a renda familiar. Grande parte trabalha no cultivo de cana (62\%), conforme observado na tabela 6. Os que não trabalham fora da safra disseram não possuir outras opções e são principalmente os mais idosos. O seguro-desemprego acaba se tornando fonte de renda para alguns dos cortadores que não possuíam contrato temporário. Os trabalhadores temporários são contratados pelas empresas por 6 meses e recontratados no ano seguinte (possivelmente pela mesma empresa).

O salário médio dessa população, no trabalho do corte, depende de duas variáveis: gênero e a idade. As figuras 3 e 4 ilustram a distribuição desigual dos 
Tabela 6 - $\mathrm{N}^{\circ}$ e \% de cortadores segundo atividades extras no período fora do corte

\begin{tabular}{lcc} 
& $\mathrm{N}$ & $\%$ \\
Plantio de cana & 25 & $62,5 \%$ \\
Usina de cana & 1 & $2,5 \%$ \\
Servente de obras & 3 & $7,5 \%$ \\
Outros serviços & 3 & $7,5 \%$ \\
Não trabalha (com seg. desemprego) & 5 & $12,5 \%$ \\
Não trabalha (sem seg. desemprego) & 3 & $7,5 \%$ \\
\hline Total & 40 & $100 \%$ \\
\hline
\end{tabular}

rendimentos auferidos pelos cortadores homens mais jovens, que recebem salários mais elevados que as mulheres, em todas as faixas etárias, e que os mais idosos, com jornadas iguais de trabalho, uma vez que o pagamento é por produção. A pesada carga laboral dos cortadores resulta de: postura física exigida para o corte, uso de ferramentas perigosas, realização de atividades repetitivas e desgastantes, transporte de material excessivamente pesado, reforçados por condições ambientais como exposição prolongada ao sol e intempéries, descargas atmosféricas, presença de animais peçonhentos e poluição do ar (Vilas Boas e Dias, 2009). Além disso, com a mecanização das áreas planas, foi transferido para os trabalhadores o corte em condições mais difíceis: terreno inclinado, plantio irregular e cana de pior qualidade (Mendonça, 2006).

Figura 3 - $\mathrm{N}^{\circ}$ de cortadores de cana entrevistados segundo salários (R\$). Macatuba, 2006

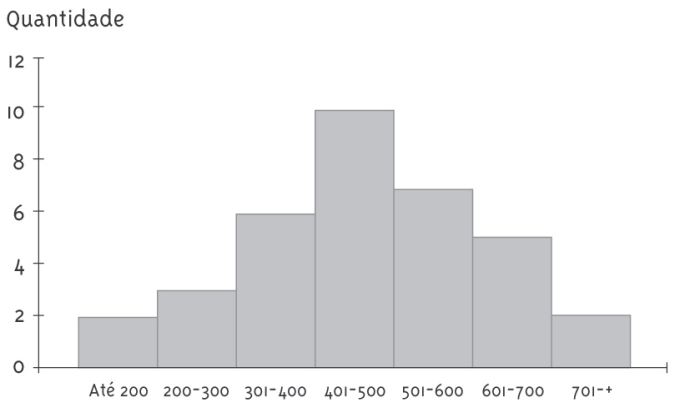

Figura 4 - Distribuições dos entrevistados segundo gênero, idade e salário

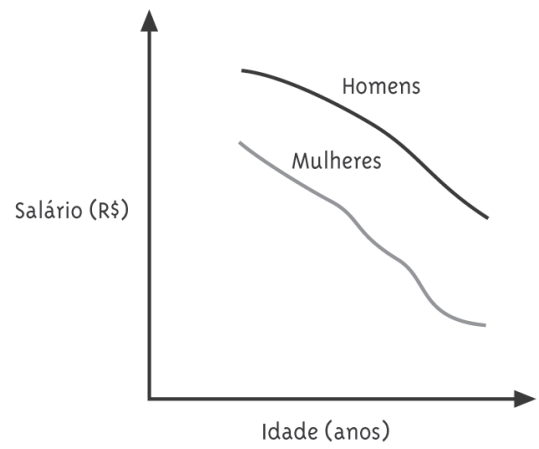

\section{Condições de saúde}

Em relação às condições saúde, buscou-se conhecer, pela entrevista, como os cortadores avaliavam sua saúde e, em seguida, quais as queixas que apresentavam sobre seu estado de saúde. A maioria dos cortadores julgou a própria saúde boa ou regular, conforme tabela 7. Uma percentagem pequena relatou más condições de saúde. Quanto às queixas de saúde indicadas, várias estão relacionadas ao processo produtivo em que estão envolvidos: dores nas costas, tosse, fadiga muscular, ardor nos olhos. Os próprios entrevistados relataram os fatores que prejudicavam sua saúde: o trabalho pesado, a poluição, a velhice e a alimentação inadequada para um trabalho que exige altíssima quantidade de energia. Os que afirmaram sentir com frequência irritação nos olhos, tosse e falta de ar, alegaram que esses sintomas têm maior intensidade na época das queimadas. Nos dias e semanas em que a média cortada aumenta, é mais comum os cortadores sentirem ora fadiga muscular, ora dor nas costas, ou ambos. Laat e colaboradores (2009), em avaliação realizada em campo sobre o trabalho dos cortadores, verificaram que, na amostra analisada, em média, o grupo ultrapassou a carga cardiovascular prescrita de $30 \%$ e verificou um ciclo médio de corte de 5,6 segundos, que caracteriza a atividade como extremamente repetitiva e com risco de lesões osteomusculares. Quando a dor é incontrolável, eles procuram auxílio no Posto de Saúde, ou não trabalham até a dor passar. Não recebem nada 
pelos dias em que não trabalharam, mesmo quando a falta é justificada com atestado médico. Em dias de chuva, se houver impossibilidade de corte, também não são remunerados.

O bairro utilizado para estudo é dotado de um Posto de Saúde, no qual os entrevistados se tratam e onde são oferecidos consulta e tratamento para problemas menos graves de saúde, segundo os entrevistados. Em casos mais graves, os pacientes são transportados para alguma cidade maior que tenha hospital público bem equipado. Entre os problemas crônicos de saúde mais comuns, foram relatados: a pressão alta (12 indivíduos), de nervos ( 5 indivíduos), asma (4 indivíduos) e doenças do coração (4 indivíduos). A maioria das doenças foi informada a eles em consulta médica e grande parte dos tratamentos ocorreu ou no Posto de Saúde ou em casa.

$\mathrm{O}$ acidente de trabalho mais comum relatado foi o corte, em geral do dedo ou do braço, ocorrido ao manejar o facão.

\section{Perspectivas em relação à lei e ao trabalho}

Um clima de incerteza está substituindo a garantia de trabalho do cortador. Muitos dos entrevistados disseram já ter visto ao vivo ou na televisão como funciona a máquina colheitadeira. A respeito da lei que estabelece o cronograma para o fim da queima nos canaviais, 35 dos 40 entrevistados relataram saber de sua existência e 25 sabiam da sua motivação ambiental. Relataram ter recebido essa informação principalmente dos meios de comunicação e dos vizinhos do bairro. O motivo da lei foi considerado correto por aqueles que apontaram os motivos ambientais e de saúde. Os que desconheciam os motivos sabiam ao menos que ela trará algum impacto para seu cotidiano. Alguns se disseram contentes, pois o fim da queima eliminará grande parte da poluição que respiram, melhorando a sua qualidade de vida principalmente das crianças, que são as que mais sofrem com as queimadas, segundo os entrevistados.

Na perspectiva da abolição do corte manual e de sua substituição pelas máquinas, somente metade dos cortadores entrevistados apresentaram planos alternativos de trabalho. Poucos deles planejam estudar, pois dizem não ter mais idade para isso ou porque abandonaram os estudos há muitos anos. No entanto, o principal motivo apontado foi a falta de tempo livre para os estudos, a falta de incentivo e de cursos profissionalizantes, e a inviabilidade econômica, não só para pagar um curso privado, mas para reduzir a jornada de trabalho para estudar. Segundo eles, as crianças e jovens possuem maior diversidade de opções, mas para os adultos não há opções educacionais nos arredores. Para seus filhos, os cortadores desejam, em geral, que eles façam cursos profissionalizantes ou faculdade para terem uma qualidade de vida melhor que a deles. Alguns responderam desejar qualquer coisa para os filhos menos que cortem cana, deixando explícita a situação indesejada em que eles se encontram. É interessante verificar como a responsabilização para a falta de estudos desse grupo recai, sobretudo, sobre a família. Parece não haver entre eles a consciência de que sua exclusão social pode ser um processo socialmente determinado e que a ausência ou omissão do estado está relacionada às incertezas com que convivem.

\section{Tabela 7 - No e \% de cortadores segundo estado de saúde relatado. Macatuba, 2006}

\begin{tabular}{lcc} 
Estado de saúde & N & $\%$ \\
Muito bom & 8 & 20,0 \\
Bom & 13 & 32,5 \\
Regular & 16 & 40,0 \\
Ruim & 2 & 5,0 \\
Muito ruim & 1 & 2,5 \\
\hline Total & 40 & 100 \\
\hline
\end{tabular}

Tabela 8 - $\mathbf{N}^{\circ}$ de cortadores segundo problemas de saúde relatados. Macatuba, 2006

$\begin{array}{lc}\text { Problema de saúde } & \text { N } \\ \text { Dor nas costas } & 23 \\ \text { Falta de ar } & 10 \\ \text { Fadiga muscular } & 19 \\ \text { Irritação nos olhos } & 18 \\ \text { Tosse } & 14\end{array}$


Tabela 9 - $\mathrm{N}^{\circ}$ de cortadores segundo trabalho que pretendem fazer depois do corte manual da cana. Macatuba, 2006

\begin{tabular}{lc} 
Trabalho que pretendem fazer & N \\
Estudar & 1 \\
Agricultura & 2 \\
Indústria & 5 \\
Serviços em geral & 5 \\
Aposentar-se & 4 \\
Não sabe/qualquer coisa & 19 \\
Já fazem outro trabalho & 2 \\
Outros/sem resposta definida & 2 \\
\hline Voltariam aos estudos & \\
\hline Sim & 20 \\
Não & 20 \\
\hline Total & 40 \\
\hline
\end{tabular}

Entretanto, a outra metade dos entrevistados mostrou-se disposta a voltar a estudar para ter uma profissão ou até mesmo para aprender a ler e escrever. É essencial observar esse interesse e considerá-lo em projeto de inserção social para a população. Alguns dentre os jovens conseguem empregos melhores, mas necessitam de formação técnica mais sofisticada, que a cidade não oferece. A falta de qualificação ainda é um problema não só para adultos e idosos, mas também para jovens. Cerca de 30\% das vagas do Programa de Auxílio ao Trabalhador (PAT) não conseguem ser preenchidas devido à falta de qualificação para atividades oferecidas.

A respeito das condições de trabalho, foram apontadas duas reivindicações pelos cortadores: melhores facões e melhores banheiros no local de trabalho. A primeira se deve ao fato de os pregos que prendem a lâmina ao cabo se desgastarem facilmente e, em certos casos, liberarem a lâmina e causarem acidentes, como o corte de dedo ou braço. Quanto aos banheiros, chamados popularmente de "cones", são pequenas ocas feitas de palha, que, em alguns casos, nem buraco na terra possuem. Verifica-se que essas são reivindicações muito básicas e os cortadores não têm consciência de direitos mais amplos, como emprego, estudos, formação profissional, saúde no trabalho. Quanto às condições de saúde dos cortadores, as usinas têm feito exames médicos periódicos, principalmente depois das denúncias apontadas pela mídia e pelo Ministério Público a respeito de péssimas condições de trabalho e dos casos de morte. 0 primeiro exame feito num recém-contratado é rígido, para que se conheça suas condições de saúde para realizar o trabalho. Um entrevistado disse que há migrantes vêm de outro estado com enfermidades, principalmente doença de Chagas.

O caso de pequenas cidades, como Macatuba, é diferente do das cidades médias, em que grande parte dos cortadores é migrante de outras regiões do país, que não costuma frequentar a cidade e mora nos alojamentos das usinas. Eles praticamente não participam da vida urbana da cidade e vivem outras angústias que os trabalhadores residentes permanentes no estado, mas que não foram objeto desta pesquisa.

\section{Discussão}

A Saúde Ambiental, ao defender a eliminação da queima da cana-de-açúcar, defronta-se com a busca de alternativas de inclusão dos cortadores e suas famílias. É fundamental que as soluções levem em conta as características do grupo, se tem moradia fixa no estado ou se migra periodicamente para trabalhar. Em Macatuba, os trabalhadores rurais entrevistados construíram um espaço de convivência na zona urbana, sejam migrantes ou não. Nesses casos, o grupo deverá ser inserido em novas condições e tipos de trabalho, ou seja, em um novo cotidiano.

Como observado na pesquisa, a maioria dos jovens frequentou regularmente a escola, e a metade dos entrevistados, de diferentes idades, mostrou-se disposta a estudar novas técnicas ligadas à agricultura. Isso deve ser levado em conta. No entanto, se a maior porção territorial dessas zonas canavieiras continuar a ser cultivada exclusivamente para canade-açúcar e o cultivo for cada vez mais mecanizado, como vem ocorrendo, não haverá opção para essa população continuar a trabalhar no campo e morar nesses núcleos urbanos menores, de função rural.É bem provável que ela se veja forçada a migrar para centros urbanos de maior porte, ou para a capital do estado. Dois pontos estão subjacentes ao entendimento da situação de exclusão/inclusão social desse grupo social. Um deles é o fato de a maior parte ser 
proprietária de sua moradia que, apesar de simples, é mais adequada que em áreas de habitação subnormal, que proliferam nas grandes cidades, e livre de aluguel. Esse pode ser um fator de estabilidade territorial para essa população, mas não por muito tempo, se não houver opções de emprego e renda para os mais jovens, uma vez que os mais velhos podem viver da aposentadoria rural. O outro ponto é que essa não é uma população muito politizada, que reivindique seus direitos, e os movimentos sociais que historicamente lutam por inclusão das classes trabalhadoras (Adorno, 2006) têm tido atuação restrita em defesa deles. Como ilustração, no esforço para aumentar a produtividade do trabalho, houve um aumento do desgaste físico dos trabalhadores. Isso fez com que muitas usinas adotassem a ginástica laboral e o fornecimento de suco com componente a base de sódio, glicose e outros minerais para reposição eletrolítica após o meio-dia, para reduzir cãibras (Jornal de Unesp, 2003). Esse suco deixou de ser oferecido aos cortadores de Macatuba havia dois anos e eles aceitaram o fato, como se o fornecimento constituísse generosidade do empregador, que podia ser suprimida à vontade.

A reforma agrária vem sendo apresentada como uma opção para a permanência da população de atividade agrária no campo. No entanto, até assentamentos têm se inserido na lógica da produção sucroalcooleira. Uma proposta alternativa seria que parte desses agricultores produzisse alimentos para as próprias regiões canavieiras, baseando-se em princípios da agroecologia, adaptada às condições naturais de clima e solo e com uso reduzido de insumos agrícolas impactantes ao meio ambiente (Altieri, 200o).

A indústria sucroalcooleira está necessitada de mão de obra qualificada, devido ao intenso crescimento que vem enfrentando. Em abril de 2007 , segundo a Fiesp ${ }^{10}$, haviam sido criadas 52 mil vagas de emprego na indústria do estado, a maior alta do ano e a maior variação para o mês de abril desde 200o. A indústria de açúcar e álcool foi responsável por $82 \%$ dessas novas vagas na indústria do estado, gerando 42 mil postos no mês em que se iniciava a safra de cana. Não se sabe quantos desses postos foram preenchidos por ex-cortadores, mas pelo relato dos entrevistados, raros são os cortadores e ex-cortadores que têm formação suficiente para se inserir nas indústrias novas ou ampliadas. A capacitação dos cortadores para que essa inserção ocorra é crucial. Governo e produtores, conscientes disso anunciaram, em meados de 2009, um programa de requalificação de trabalhadores da cana-de-açúcar, o "Compromisso Nacional para Aperfeiçoar as Condições de Trabalho na Cana-de-Açúcar”, que será um mecanismo de reconhecimento de empresas que cumprirão um conjunto de boas práticas trabalhistas acima da legislação vigente, envolvendo o setor privado, os trabalhadores e o Governo Federal (Unica, 2009) ${ }^{11}$.

\section{Considerações Finais}

O trabalho manual do corte de cana está no início de seu fim, ou será muito restrito às áreas de maior declividade que não puderem ser colhidas mecanicamente. Um futuro includente para a população de cortadores que perderá o emprego, baseando-se em princípios de justiça ambiental e social, é urgente. Entretanto, só será possível se houver investimentos das empresas e do governo para que outros tipos de trabalho possam ser realizados. O exemplo do estado de São Paulo, livre de queimadas, provavelmente será seguido por outros estados e nações que cultivam cana. É, portanto, necessário encontrar alternativas viáveis de inserção da população cortadora em outras atividades econômicas, para que ela não seja "obrigada" a sair de seus espaços de moradia e de vida em cidades de pequeno e médio porte em busca de empregos nas cidades grandes. A história das metrópoles brasileiras é repleta de casos em que desequilíbrios no campo causam o deslocamento de pessoas para os grandes centros, onde eles se transformam em "excluídos", vivendo em bairros sem qualquer infraestrutura, em áreas não legalizadas.

A educação geral e técnica terá papel fundamental no desencadear da inserção dessa população em

10 Álcool puxa emprego na indústria de SP, In: Folha de S.Paulo, 11 maio 2007, Caderno Dinheiro, p. B14.

11 Discurso do presidente da Unica, Marcos Jank no Ethanol Summit, em 2009. 
novos tipos de trabalho, na agricultura, indústria, comércio e serviços. Mas só isso não basta. Projetos de desenvolvimento rural para pequenas comunidades precisam ser implantados, fixando os trabalhadores rurais no campo ou em centros urbanos menores e dotados de infraestrutura. A pesquisa mostrou que a maioria dos cortadores de cana gosta do local onde mora, está acostumada na lida com a terra e está mais apta a continuar a trabalhar na terra do que mudar de ambiente de trabalho. A pressão para que novas áreas sejam ocupadas pelos produtores de cana-de-açúcar continua muito grande. A monocultura de larga escala, fruto de uma ação totalitária do capital agroindustrial no espaço, fragiliza a economia dessas zonas, por se sustentar num só tipo de produto que eventualmente pode sofrer queda de preço e levar toda a população à crise. Por isso, é necessário que haja incentivos às regiões para manter fazendas agroecológicas, visando a sustentabilidade ambiental, social e econômica, diversificando a ocupação do solo, os trabalhos rurais, e atenuando os males da monocultura.

A dificuldade que os cortadores de cana apresentaram quanto às perspectivas de trabalho e de vida faz parte de um processo, denominado por Santos (2003, p. 29), de pobreza planejada. Segundo o autor, essa pobreza é mascarada pela promoção de alguns investimentos sociais que, na realidade, apenas fornece maior renda e consumo de bens e serviços a essa população, mas não promove inserção social significativa, pois a desigualdade é mantida. Segundo Zioni (2006), o conceito de pauperismo difere daquele de exclusão.

Ambos os termos remeteriam a situações precárias de trabalho, à ausência de qualificação, ao desemprego e à incerteza sobre o futuro, mas a similitude não seria total porque, enquanto o primeiro seria explicado pela situação de barbárie do início da industrialização, a noção de exclusão seria entendida atualmente como um processo de afastamento de populações menos qualificadas (Zioni, 2006, p. 19).

O desafio está em superar essa situação em diferentes escalas territoriais. As políticas ambien- tais não podem ser causa de injustiças sociais, de exclusão social e de desequilíbrios populacionais, como foram muitas políticas econômicas e o próprio processo histórico em que se dá a economia capitalista (Adorno, 2006). A sua outra face tem que ser a inclusão social em políticas e projetos pensados em escalas locais, regionais, nacionais e globais, protegendo o meio ambiente, mas equilibrando a economia e diversificando o trabalho. A região pode se adaptar a demandas do espaço global por biocombustíveis, porém sem destruir suas particularidades positivas e sem gerar rupturas de condições sociais que podem gerar fluxos migratórios de consequências imprevisíveis.

\section{Referências}

ADORNO, R. C. F. Exclusão, insegurança, vulnerabilidades: incluir com o acesso à saúde? Saúde e Sociedade, São Paulo, v. 15, n. 3, p. 7-14, 2006. ALVES, F. Por que morrem os cortadores de cana? Saúde e Sociedade, São Paulo, v. 15, n. 3, p. 9o-98, 2006.

ALTIERI, M. Agroecologia: a dinâmica produtiva da agricultura sustentável. 2. ed. Porto Alegre: Ed. UFRGS, 2000.

ARBEX, M. A. Avaliação dos efeitos do material particulado proveniente da queima da plantação de cana-de-açúcar sobre a morbidade respiratória na população de Araraquara-SP. 2001. Tese (Doutorado em Ciência) - Faculdade de Medicina da Universidade de São Paulo, São Paulo, 2001.

ARBEX, M. A. et al. Assessment of the effects of sugarcane plantation burning on daily counts of inhalation therapy. Journal of Air and Waste Management Association, Pittsburgh, v. 50, n. 10, p. 1745-1749, 2000.

ARBEX, M. A. et al. Queima de biomassa e efeitos sobre a saúde. Jornal Brasileiro de Pneumologia, Brasília, DF, v. 30, n. 2, p. 158-175, 2004.

BRAUNBECK, O. A.; MAGALHÃES, P. S. G. Colheita sustentável com aproveitamento integral da palha. Visão Agrícola, Piracicaba, v. 1, n. 1, p. 72-78, 2004. 
CANASAT. Mapeamento de cana via imagens de satélite de observação da terra. São José dos Campos: INPE, 2009. Disponível em: < http://www. dsr.inpe.br/mapdsr/>, Acesso em: 20 set. 2009.

CANÇADO, J. E. D. et al. Repercussões clínicas da exposição à poluição atmosférica. Jornal Brasileiro de Pneumologia, Brasília, DF, v. 32, p. S5-S11, 2006. Suplemento 2.

DIÁRIO OFICIAL DO ESTADO DE SÃO PAULO. Poder Legislativo. p.14; o8/fev/2007. Projetos de lei: Projeto de lei $n^{0}{ }_{14}$, de 2007 . Assembléia Legislativa do Estado de São Paulo. Disponível em: <http://www.imprensaoficial.com.br/PortalIO/DO/ BuscaD02001Documento_11_4.aspx?link=/2007/ legislativo/fevereiro/o8/pag_oo14_3SQoVETV23JF 2e62MV98N77oM95.pdf\&pagina=14\&data=08/02/ $2007 \&$ caderno $=$ Legislativo \&paginaordenacao $=100$ 14>. Acesso em: o3 fev. 2010.

GELLER, H. S. Revolução energética: políticas para um futuro sustentável. Rio de Janeiro: Relume Dumará: USAID, 2003.

GOVERNO DO ESTADO DE SÃO PAULO. Secretaria de Estado de Meio Ambiente. Relatório Etanol Verde 2009. São Paulo, 2009. Disponível em: <http://www.homologa.ambiente.sp.gov.br/ etanolverde/>. Acesso em: 23 jun. 2009.

IBGE - INSTITUTO BRASILEIRO DE GEOGRAFIA E ESTATÍSTICA. Censo Agropecuário 20o6. Rio de Janeiro, 2006. Disponível em: <http://www.ibge. gov.br/home/estatistica/economia/agropecuaria/ censoagro/20o6/agropecuario.pdf>. Acesso em: 15 maio 2007.

JORNAL DA UNESP. 2003. 198. 8-9.

LAAT, E. F. et al. Impacto sobre as condições de trabalho: o desgaste físico dos cortadores de canade-açúcar. In: PLATAFORMA BNDES. Impactos da indústria canavieira no Brasil. Rio de Janeiro: IBASE, 2009. Disponível em: <http://www. plataformabndes.org.br/index.php/pt/biblioteca/ doc_view/18-impactos-da-industria-canavieira-nobrasil?tmpl=component\&format=raw $>$. Acesso em: 24 jun. 2009.
LOPES, F. S.; RIBEIRO, H. Mapeamento de internações hospitalares por problemas respiratórios e possíveis associações à exposição humana aos produtos da queima de palha de canade-açúcar (Saccharum sp) no Estado de São Paulo. Revista Brasileira de Epidemiologia, São Paulo, v. 9, n. 2, p. 215-225, 2006.

MENDONÇA M. L. A OMC e os efeitos destrutivos da indústria da cana no Brasil. 2006. Disponível em: <http://www.acaoterra.org/display. php?article=397 $>$. Acesso em: 24 jun. 2009.

RIBEIRO, H.; ASSUNÇÃO, J. V. Efeitos das queimadas na saúde humana. Estudos Avançados USP, São Paulo, n. 44, p. 125-148, 2002.

RIBEIRO, H. Queimadas de cana-de-açúcar no Brasil: efeitos à saúde respiratória. Revista de Saúde Pública, São Paulo, v. 42, n. 2, p. 370-376, 2008.

RIPOLI, L. M. C. Mapeamento do palhiço enfardado de cana-de-açúcar (saccharum sp.) e do seu potencial energético. 2002. Dissertação (Mestrado em Agronomia) - ESALQ, Piracicaba, 2002.

SANTOS, M. Economia espacial. São Paulo: EDUSP, 2003.

SILVA, M. A. M. Trabalho e trabalhadores na Região do "Mar de Cana e do Rio de Álcool”. Revista Agrária, São Paulo, n. 2, p. 2-39, 2005. UNICA - UNIÃO DA INDÚSTRIA DE CANA-DEAÇÚCAR. Protocolo Agroambiental do Setor Sucroalcooleiro. São Paulo, 2009. Disponível em: <http://www.unica.com.br/content/show. asp? cntCode $=\{$ BEE1o6FF-DoD5-4264-B1B37EoC7D4031D6\}>. Acesso em: 23 jun. 2009.

VILAS BOAS, S. W.; DIAS, E. C. Contribuição para a discussão sobre as políticas no setor sucroalcooleiro e as repercussões sobre a saúde dos trabalhadores. In: PLATAFORMA BNDES. Impactos da indústria canavieira no Brasil. Rio de Janeiro, IBASE, 2009. Disponível em: <http://www. plataformabndes.org.br/index.php/pt/biblioteca/ doc_view/18-impactos-da-industria-canavieira-nobrasil?tmpl=component\&format=raw $>$. Acesso em: 24 de jun. 2009 
ZANCUL, A. O efeito da queimada de canade-açúcar na qualidade do ar na região de Araraquara-SP. 1998. Dissertação (Mestrado em Engenharia) - Escola de Engenharia de São Carlos - USP, São Carlos, 1998.

ZIONI, F. Exclusão social: noção ou conceito?

Saúde e Sociedade, São Paulo, v. 15, n. 3, p. 15-29, 2006. 